\title{
The Recovery Process Utilizing Erikson's Stages of Human Development
}

\author{
Suzanne E. Vogel-Scibilia - Kathryn Cohan McNulty • \\ Beth Baxter · Steve Miller · Max Dine • \\ Frederick J. Frese III
}

Received: 8 April 2008/Accepted: 23 February 2009/Published online: 17 June 2009

(C) The Author(s) 2009. This article is published with open access at Springerlink.com

\begin{abstract}
Of current interest to the field are clinical frameworks that foster recovery. The authors offer a psycho-developmental model that parallels Erik Erikson's theory of human development, and theorize that the process of psychiatric recovery involves a psychic reworking of these fundamental steps. Understanding recovery in this context allows the client and the practitioner of psychiatric rehabilitation to design and implement a coherent treatment strategy.
\end{abstract}

Keywords Recovery - Psychodevelopment .

Psychiatric rehabilitation · Erikson · Counseling

\section{Introduction}

While the use of scientific evidence-based practices can be integrated into the recovery model of mental health treatment (Frese et al. 2001), there is no equivalent process for psycho-developmental principles. Researchers have noted

S. E. Vogel-Scibilia - K. C. McNulty · B. Baxter - S. Miller M. Dine - F. J. Frese III

National Alliance on Mental Illness (NAMI),

Arlington, VA, USA

S. E. Vogel-Scibilia

Western Psychiatric Institute and Clinic, Pittsburgh, PA, USA

F. J. Frese III

Northeastern Ohio Universities, College of Medicine,

Rootstown, OH, USA

S. E. Vogel-Scibilia $(\bowtie)$

Beaver Co. Psychiatric Services, 219 Third Street, Beaver, PA 15009, USA

e-mail: svs2u@hotmail.com that mental health professionals may react with perplexity or negativity when discussing how to integrate recovery into psychiatric care (Drake 2000). A recent Pennsylvania Consensus Conference on Recovery documented a total of 12 barriers to promoting recovery for persons with mental illness (Rogers et al. 2007). This dilemma may occur because there is no concrete theory that translates into useful clinical interventions that promote recovery in consumers seeking recovery-oriented care from traditional providers. In this article, a psycho-developmental recovery model which closely parallels Erikson's eight stages of human development (Erikson 1968) is discussed.

There is strong support for the tenets of this recovery model. One early publication commented on the need to transform the recovering person's self concept into a more "functional sense of self" that is a dynamic and responsible agent for recovery (Davidson and Strauss 1992). Since then, many authors have discussed the key concepts of personal understanding and self-determination (Shattell et al. 2007; Bellack 2006; Davidson et al. 2008a, b; Farkas 2007). Other authors have stressed the importance of empowerment as well as instilling vital hope and optimism (Resnick et al. 2004, 2005; Davidson and Strauss 1995; Schrank et al. 2008).

The National Consensus Statement on Mental Health Recovery (United States Department of Health and Human Services 2005) has identified ten fundamental components of recovery-self-direction, individualized and personcentered, empowerment, holistic, non-linear, strengthsbased, peer-support, respect, responsibility and hope. All these components are integrated into this developmental model which melds known concepts of recovery into an understandable, practical framework that allows transformation of traditional programs and therapeutic contacts into recovery-oriented services. 


\section{Description of the Clinical Theory and Recovery Model}

The authors, all consumers with serious mental illness, have developed these stages through their personal recoveries from psychiatric illness. Some of the authors apply these concepts in their clinical practices. This model can assist conventional practitioners by offering a familiar therapeutic framework that fosters hope, empowerment and self-determination in individuals who are finding their unique recovery path. In various settings, in recent years, this concept has been well received (Vogel-Scibilia 20022008). The authors propose eight opportunities to resolve conflict in the service of personal growth and development, which parallels Erikson's eight stages. Vignettes from the authors' experience, altered to preserve confidentiality, illustrate each stage.

Our hypothesis is that one element of recovery is the work of resolving the positive and negative aspects of each recovery phase which parallels normal, non-pathologic development for all human beings regardless of race, gender, religion, ethnicity, or sexual orientation. It is crucial to realize that even though Erikson's schema is linear, our recovery framework is not, just as the process of recovery is not linear. These non-linear opportunities are proposed as a progression through stages, then setbacks, followed by mastered learning and spiritual growth. Recovering consumers often slide between adjoining stages. At the onset of a clinical relapse or an environmental challenge, consumers may start back at the initial stage, questioning whether recovery is possible and proceeding to work through previously addressed steps to restart progress towards recovery.

Each consumer's path through this model is unique based on one's personal strengths and resiliency. This selfdirected recovery journey is holistic and involves all aspects of the recovering life. It is important to grasp that this model does not pathologize recovery, but relates it to innate human development for all people. Some individuals have criticized Erikson's model as not being sensitive to racial, gender or ethnic issues. While Erikson's developmental model was crafted by individuals of the white majority of the 1960s era, we believe that our recovery model translates to all individuals regardless of ethnic, religious, gender, racial or sexual orientation. Let us discuss each Eriksonian stage and the corresponding recovery phase sequentially (see Tables 1, 2, 3).
Table 1 Comparison of human development and recovery stages

\begin{tabular}{lll}
\hline & $\begin{array}{l}\text { Developmental stages } \\
\text { of recovery }\end{array}$ & $\begin{array}{l}\text { Erikson's stages of human } \\
\text { development }\end{array}$ \\
\hline Stage 1 & Trust versus doubt & $\begin{array}{l}\text { Trust versus mistrust } \\
\text { Stage } 2\end{array}$ \\
Stage 3 & Hope versus shame & Initiative versus guilt \\
Stage 4 & Empowerment versus guilt & Industry versus inferiority \\
Stage 5 & Action versus inaction & Identity versus identity diffusion \\
Stage 6 & New self versus sick self & Intimacy versus isolation \\
Stage 7 & Intimacy versus isolation & Generativity versus stagnation \\
Stage 8 & Purpose versus passivity & Integrity versus despair \\
\hline
\end{tabular}

Table 2 Mental illness recovery stages

\begin{tabular}{|c|c|c|c|c|c|}
\hline $\begin{array}{l}\text { Mental illness } \\
\text { recovery stage }\end{array}$ & Features & & $\begin{array}{l}\text { Erikson } \\
\text { developmental stage }\end{array}$ & Features & \\
\hline $\begin{array}{l}\text { Trust versus } \\
\text { doubt }\end{array}$ & $\begin{array}{l}\text { Acceptance of } \\
\text { psychiatric disability }\end{array}$ & $\begin{array}{l}\text { Trust in the concept } \\
\text { of recovery }\end{array}$ & Trust versus mistrust & $\begin{array}{l}\text { Is the world } \\
\text { reliable? }\end{array}$ & $\begin{array}{l}\text { Will my needs be } \\
\text { met? Result: Hope }\end{array}$ \\
\hline $\begin{array}{l}\text { Hope versus } \\
\text { shame }\end{array}$ & $\begin{array}{l}\text { Grapple with loss of } \\
\text { control of one's } \\
\text { mind; illness } \\
\text { symptoms }\end{array}$ & $\begin{array}{l}\text { Coping skill } \\
\text { development; } \\
\text { Hope for personal } \\
\text { recovery }\end{array}$ & $\begin{array}{l}\text { Autonomy versus } \\
\text { Shame/Self doubt }\end{array}$ & $\begin{array}{l}\text { Struggle for } \\
\text { personal } \\
\text { control }\end{array}$ & $\begin{array}{l}\text { Understanding of } \\
\text { separation from } \\
\text { others. Result: Will }\end{array}$ \\
\hline $\begin{array}{l}\text { Empowerment } \\
\text { versus guilt }\end{array}$ & $\begin{array}{l}\text { Address frustration and } \\
\text { anger; empower self; } \\
\text { minimize disability }\end{array}$ & $\begin{array}{l}\text { Focus on } \\
\text { empowerment; } \\
\text { Search for } \\
\text { personal recovery } \\
\text { plan. Use } \\
\text { strengths; } \\
\text { banish guilt }\end{array}$ & $\begin{array}{l}\text { Initiative versus } \\
\text { guilt }\end{array}$ & $\begin{array}{l}\text { Concept of } \\
\text { autonomy to } \\
\text { pursue new } \\
\text { tasks }\end{array}$ & $\begin{array}{l}\text { Use of new-found skills } \\
\text { to cope with disability } \\
\text { and advance recovery. } \\
\text { Result: Purpose }\end{array}$ \\
\hline
\end{tabular}


Table 3 Mental illness recovery stages (continued)

\begin{tabular}{|c|c|c|c|c|c|}
\hline $\begin{array}{l}\text { Mental illness } \\
\text { recovery stage }\end{array}$ & Features & & $\begin{array}{l}\text { Erikson } \\
\text { developmental stage }\end{array}$ & Features & \\
\hline $\begin{array}{l}\text { Action versus } \\
\text { inaction }\end{array}$ & $\begin{array}{l}\text { Fight static disability } \\
\text { \& isolation; create } \\
\text { "social niche" }\end{array}$ & $\begin{array}{l}\text { Seek purposeful } \\
\text { work \& leisure } \\
\text { pursuits }\end{array}$ & $\begin{array}{l}\text { Industry versus } \\
\text { inferiority }\end{array}$ & $\begin{array}{l}\text { Acquire skills and } \\
\text { interests }\end{array}$ & $\begin{array}{l}\text { Build self-esteem. } \\
\text { Result: Competence }\end{array}$ \\
\hline $\begin{array}{l}\text { "New" self versus } \\
\text { "Sick" self }\end{array}$ & Am I my disease? & $\begin{array}{l}\text { Separate personal } \\
\text { identity from } \\
\text { illness }\end{array}$ & $\begin{array}{l}\text { Identity versus role } \\
\text { confusion }\end{array}$ & $\begin{array}{l}\text { Who am I? What are } \\
\text { my values and } \\
\text { self-concepts }\end{array}$ & $\begin{array}{l}\text { Personal identity and adult } \\
\text { role development } \\
\text { Result: Fidelity }\end{array}$ \\
\hline $\begin{array}{l}\text { Intimacy versus } \\
\text { isolation }\end{array}$ & $\begin{array}{l}\text { Establish intimate } \\
\text { relationships; } \\
\text { integrate recovery }\end{array}$ & $\begin{array}{l}\text { Seek out intimacy } \\
\text { with a peer to } \\
\text { share recovery life }\end{array}$ & $\begin{array}{l}\text { Intimacy versus } \\
\text { isolation }\end{array}$ & $\begin{array}{l}\text { Engaging in intimate } \\
\text { relationships; } \\
\text { sharing life with a } \\
\text { peer }\end{array}$ & $\begin{array}{l}\text { Development of intimate } \\
\text { relationships with peers. } \\
\text { Result: Love }\end{array}$ \\
\hline $\begin{array}{l}\text { Purpose versus } \\
\text { passivity }\end{array}$ & $\begin{array}{l}\text { Establishing a "life } \\
\text { niche"; altruistic } \\
\text { giving back }\end{array}$ & $\begin{array}{l}\text { Living well with a } \\
\text { mental illness }\end{array}$ & $\begin{array}{l}\text { Generativity versus } \\
\text { stagnation }\end{array}$ & Is this all there is? & $\begin{array}{l}\text { Accomplishing meaningful } \\
\text { goals in life. Result: Care }\end{array}$ \\
\hline $\begin{array}{l}\text { Integrity versus } \\
\text { despair }\end{array}$ & $\begin{array}{l}\text { Reflecting on life } \\
\text { lived with } \\
\text { psychiatric recovery }\end{array}$ & $\begin{array}{l}\text { Provide mentorship } \\
\text { and wisdom }\end{array}$ & $\begin{array}{l}\text { Integrity versus } \\
\text { despair }\end{array}$ & $\begin{array}{l}\text { Looking back on the } \\
\text { life that one has } \\
\text { lived }\end{array}$ & $\begin{array}{l}\text { Life review and addressing } \\
\text { mortality. Result: Wisdom }\end{array}$ \\
\hline
\end{tabular}

\section{Stage One}

Mental illness recovery stage

Erikson developmental stage

Erikson's first stage of human development, trust versus mistrust, addresses the individual's infantile experiences with the world other than himself. Is the world reliable and are object relations consistent and available? For the person with a psychiatric disability, the first recovery stage, trust versus doubt, occurs at the onset of the disability and involves acceptance of the event of mental illness, as well as trust in the fundamental concept of recovery.

Recovery courses have endorsed the trauma theory of psychiatric distress-comparing persons with new onset disability to trauma survivors suffering from post-traumatic shock (Burland 2000; McNulty 2006). Stage-specific dependency crises may drive the use of primitive defense mechanisms such as denial and projection. This may result in the person being labeled with an Axis II disorder that is not reflective of long term personality architecture. The recovering person's ability to utilize more complex coping skills may be limited not only by the severity of the disability, but also by the newness of the psychiatric symptoms and lack of learned experience. Denial of disability may not be a chronic condition; rather it may be the overwhelming, initial reaction of a grief-stricken survivor. The practitioner's task is to address stage-appropriate denial and projection while maintaining necessary collaboration through this difficult period.

The trust versus doubt dichotomy may more directly involve the practitioner when the person in recovery ponders the consistency and accessibility of treatment similar to the consistency and acessibility of outside objects in Erikson's model. Motives may be questioned. "Did my family put you up to this?" "Do you just want to take my money?" Practitioners need to model the clientcentered tenor of the therapeutic relationship by adopting a hopeful recovery tone that does not hinder formation of a strength-based, individualized consumer-driven recovery plan. This tone forms the foundation for the recovery work to follow. The fostering of dependency or the creation of feelings of dis-empowerment during this phase are examples of iatrogenic complications of non-recovery based care.

A 45 year old woman with rapid cycling bipolar symptoms is unable to obtain an emergent medication change at her over-crowded psychiatric clinic and is "triaged" to the local emergency room. After waiting five hours, she is told by the psychiatric crisis nurse that he can't change her medicine nor admit her to the hospital because she is not dangerous. The woman, exhausted and feeling dis-empowered, angrily cries out- "do I have to come to your emergency room with my wrists bleeding to get a medication change?" She later requires four point restraints when informed that she had been involuntarily committed by nervous physicians due to those statements. The medication change occurred on an inpatient unit but at great cost to her recovery. At last contact, many years later, she is still struggling with the trust-doubt recovery stage. As a consequence of her treatment-related trauma, she continues to reject all voluntary medical and psychiatric emergency services. 


\section{Stage Two}

Mental illness recovery stage

Hope versus shame

Erikson developmental stage

Autonomy versus shame/self-doubt

Erikson's second stage, autonomy versus shame and self-doubt, involves the struggle for personal control and separation from others. The corresponding recovery stage, hope versus shame, involves grappling with the loss of control over one's mind and the acceptance of a personal recovery that may include a life that is different from premorbid expectations. This crisis resolves with the cognitive understanding that recovery often is not returning to ideals from the past, but rather moving forward to embrace a meaningful life that contains disability. The recovering person grieves the loss of the previous mental experience, and searches for ways to adapt to a new mental landscape involving self-direction and responsibility. This phase mirrors the Eriksonian struggle to learn new autonomous tasks. Some may focus intense attention towards learning the "rules" of having a psychiatric disability and obtaining treatment, while others react to minor medication side effects or find reasons to discontinue medication or therapy. They may engage in power struggles, questioning healthcare routines or the motives for suggested interventions. Anger externalized or internalized is a prominent feature of this stage and may lead to the person coming into conflict with others or engaging in self-damaging behavior. These intense emotions may be connected to the shame aspects of disability, which include: losses incurred from changes in functioning; feelings of powerlessness over control of one's mind; and internalized discrimination, or stigma. Working through these conflicts can be both extensive and prolonged, requiring endurance on the part of both practitioner and consumer, to address counter-transference impulses and avoid feeling worn down by the recovery journey.

The dichotomy of loss of control versus self-determination is an important recovery dynamic because it continues to involve dependency needs but requires the acceptance of trust acquired in the previous stage. Highly paternalistic treatment milieus often require recovering persons to seek unilateral instructions for every therapeutic bump in psychiatric care. The resulting de-valuation and powerlessness stifles recovery by blocking recovery-based initiative and the acquisition of independent problem solving skills. Several authors have acknowledged that recovery models should encourage an active, self-determined, collaborative role for recovering persons both for empowerment as well as improvements in decision-making abilities (McNulty 2006; Jacobson and Greenley 2001).

During the hope versus shame stage, the recovering person moves from a dependent to a more independent posture in relationships both inside and outside of therapy by building a repertoire of adaptive coping skills and abandoning maladaptive ones. Often prior boundaries with practitioners and caretakers are re-assessed. Peer-run or peer-supported services may provide a safer environment to practice recovery precepts especially symptom monitoring, problem solving strategies and reality testing. Encouraging consumers to actively participate in peersupport services and educational programs are fundamental aspects of assisting progress through this stage. Increased contact with others in recovery often mitigates feelings of shame and decreases isolation. Promoting illness selfmanagement skills increases hope and provides a useful outlet for autonomy drives. Multiple authors have endorsed the instillation of hope as one of the key concepts of recovery (Resnick et al. 2004, 2005; Jacobson and Greenley 2001; Mead and Copeland 2000). In addition to hope decreasing the risk of frustration based suicide attempts (Collins and Cutliffe 2003), the hope for a personal recovery plays a crucial part in the resolution of this stage.

A 35 year old computer specialist enters treatment for bipolar depression. Though he adequately addresses trust versus doubt dynamics, he becomes stuck in the shame aspects of his illness believing he is personally responsible for his disability, should have control over his symptoms and can not lead a worthwhile life. He focuses his frustration on the fact that his female psychiatrist of similar age knows his "secrets" but he is not "allowed" to know hers. His anger becomes projected onto the medication she prescribes leading him to self-discontinue numerous medication trials due to minor side effects. When extensive, intrusive personal inquiries towards the psychiatrist are addressed in session as boundary issues, the computer specialist responds by hacking into the psychiatrist's personal and financial information. When he gleefully shares his new-found knowledge with her, a more focused discussion of his boundary violations allows him to verbalize his fear that the psychiatrist views him as "damaged goods". He perceives her lack of self-disclosure as confirming this. "You would never socialize with someone like me". Step-wise exploration of his internalized stigma about psychiatric disabilities and anger over the loss of control during hypomanic episodes produced a gradual diminution of side effect complaints and extinguished his unilateral discontinuation of medication. Acceptance by the gentleman that his disability was not a character flaw allowed him to embrace the hope that a meaningful life and recovery was possible. 
Stage Three

Mental illness recovery stage Empowerment versus guilt Erikson developmental stage Initiative versus guilt

The third recovery stage, empowerment versus guilt, closely parallels Erikson's initiative versus guilt stage. Just as all individuals take their new-found skills and autonomy concept to pursue new tasks, recovering people apply newly acquired coping skills and hope for recovery to pursue empowerment, minimize disability and weather recurrent episodes or residual symptoms. While exploring their own feelings about their disability, they deal with society's perceptions and expectations. "Why don't you work?" "What is wrong with you?" "Why don't you snap out of this?"

Practitioners who provide person-focused care within the treatment planning process, who ask how the recovery work is progressing and who discuss the risks, benefits and alternatives of different interventions leading to a collaborative plan, will hasten progress through this stage and speed the process of recovery. Searching by the consumer, guided by the practitioner as a mentor, for an individualized recovery plan that utilizes personal strengths and positive capabilities will enhance personal empowerment.

The negative aspect of this dichotomy, guilt, may consume a tremendous amount of psychic energy that paralyzes progress towards recovery. Frustration and anger issues may lead to self-loathing. Changes in appearance from the medication or changes in socio-economic status due to disability often fuel this crisis. The emotion of guilt carries with it the urge to repair (Linehan 1993), but the damage can be so extensive that it overwhelms the individual's sense of self. Practitioners must be mindful of the risk of suicide since anger in this stage can be self-directed rather than projected. Recovering people may verbalize the feeling of being "worn down" by symptoms and search for ways to escape.

A 52 year old male psychologist with severe obsessive-compulsive disorder became more distant and passive over a 6 months period of multiple, relatively minor relapses that none the less produced significant employment problems. Without warning, he unsuccessfully overdosed with the clear intent to end his life. After a prolonged period of intensive inpatient treatment and support from his family, he verbalized regret about the attempt, but admitted that he didn't have the "nerve" to cope with this disabling illness. With much encouragement from his recovering consumer-provider peer group, he agreed to pursue outpatient therapy to develop a recovery plan, and included a 6 months moratorium on further suicide attempts. This allowed vital time for him to dissipate internalized anger and grieve the loss of identity that occurred when he ceased working. While his illness continued to progress, he verbalized less concern about his occupation-significant disability and did not repeat the suicidal behavior during 9 years of outpatient follow-up.

Besides attempts to escape through suicide, consumers may change residences, practitioners, jobs or geographic areas. Struggles with abandonment by friends or family members who can not cope may prolong feelings of anger and resentment leading the individual to become stuck in the "victim" role. Providers should address this sensitively and avoid the temptation to ascribe consequent behaviors to a co-morbid personality disorder. The opportunity is for a trusted practitioner to become an important source of reassurance, by combating guilt and supporting the courage and determination needed to fight a serious illness. Focusing on attaining reasonable goals that build selfesteem and expanding support networks in the community are crucial. One can suggest support groups or drop-in center participation not only as a recipient but also as a volunteer of services when the recovering person is ready. Vocational rehabilitation evaluations can be initiated. Involvement with other consumers helps to remove the personalized guilt of "what did I do to deserve this?" Towards the end of this stage, recovery-based service opportunities such as the National Alliance On Mental Illness (NAMI) programs-Peer-to-Peer mentorship, NAMI Connection facilitation and/or In Our Own Voice training may provide a focus for transition to the next stage (McNulty 2006; DeMelle 2002).

\section{Stage Four}

\begin{tabular}{ll}
\hline Mental illness recovery stage & Action versus inaction \\
Erikson developmental stage & Industry versus inferiority \\
\hline
\end{tabular}

The fourth stage of recovery, action versus inaction, has close similarity to Erikson's fourth developmental stage, industry versus inferiority. The dual dichotomies in this "energy" stage, activity versus isolation and rehabilitation versus static disability, are addressed by seeking out both greater levels of purposeful work and meaningful leisure pursuits. The conflict involves not only what to do but also how much to do without jeopardizing the improvement gained thus far. While recovery involves the pursuit of interests and activity at all stages, this focus on action involves an increase in the basic drive to be productive within one's recovery plan. Individuals often benefit from greater pursuit of vocational rehabilitation goals. During this stage, consumers consolidate these concepts within the establishment of a "social niche" for recovery. 
The practitioner's goal is to continue to foster both autonomy and industry, and to assist the recovering person in determining comfortable limits on activity. The increasing interest in goal-directed activities may cause people to miss appointments or medication. This difficulty is not pathological resistance but instead what we authors term: "distracted non-adherence". Reframing the developing recovery as occurring because psychiatric care was maintained as a priority may decrease the potential for disengagement.

Consumers who have negotiated a mutually flexible, collaborative relationship with their providers will progress more rapidly through this stage compared to a relationship where either party's rigid style may lead to a return of therapeutic power struggles. Practitioners should explore their contributions to the conflict and model problemsolving, constructive solutions.

A 32 year old woman with a severe schizoaffective disability experiences marked improvement with clozapine therapy and obtains a vocational rehabilitation scholarship for specialty training that requires an extensive commute by public transportation. The woman asks her local clinic to reassign her to a new therapist that has evening hours, but the clinic has a rigid policy. Clients can only receive a new therapist if they drop out of therapy for 1 year and then re-enter the treatment system. Not even reasonable exceptions are granted. She transfers to a private psychiatrist who offers evening appointments but he is unaware of her prior history of treatment refractory psychosis and substitutes another atypical antipsychotic medication for her clozapine. The woman rapidly relapses and has to withdraw from school. Discouraged, she transfers to a recovery-focused clinic and obtains evening hours and a restart of her prior medication. She reworked the first four recovery stages with the new practitioner and re-entered school 1 year later.

\section{Stage Five}

\begin{tabular}{ll}
\hline Mental illness recovery stage & "New" self versus "Sick" self \\
Erikson developmental stage & Identity versus role confusion \\
\hline
\end{tabular}

The fifth recovery stage, "new self" versus "sick self", parallels Erikson's fifth stage of identity versus role confusion. The transition to this stage characteristically overlaps with the final aspects of resolution of the fourth stage. In this stage the recovering person grapples with "Am I my disease?" and attempts to separate personal identity from the consequences and emotions of the disability. Language may become a focal point of discussion. Adopting person- first language such as "a person with schizophrenia" instead of "a schizophrenic" throughout the entire course of care addresses this conflict respectfully.

People become very sensitized to stigma and may rail at discrimination issues. Unfocused, or non-constructive, anger directed at internalized negative objects may impede resolution of this stage. Helping people to negotiate this stage involves processing the anger and channeling new found energy effectively, such as work involving local advocacy initiatives or volunteer activities. Many people will grapple with "coming out" to new friends or coworkers or may feel misunderstood within the "chronically normal (non-mentally ill)" community (Bilheimer 1997). Individuals may refuse to embrace a disabled role and not accept psychiatric care, especially when it appears to conflict with personal autonomy.

While some may seek out peers for support and socialization, others may avoid peer contact. Avoidance may lead to social isolation, especially if the recovering person has not re-integrated into the non-psychiatrically disabled community. Individuals may feel vulnerable from outside society's expectation to conform, especially when these expectations conflict with the realities of living with the demands of a psychiatric disability. Recovering persons may repeatedly attempt mainstream employment despite exacerbations of illness or may reject needed-but sometimes stigmatizing - mental health services. A standstill in the struggle of the fifth stage may appear as a re-awakening of denial and a subsequent withdrawal from treatment.

A 27 year old psychiatry resident develops severe major depression during the third year of training. Despite a long history of chronic, untreated anxiety and a strong family history of affective disorder, the resident refuses pharmacotherapy from a psychiatrist and consults a masters-level therapist for cognitivebehavioral interventions while self-prescribing a selective serotonin re-uptake inhibitor anti-depressant. During later periods of severe depressive symptoms, the resident crisis calls other house staff in the middle of the night. The residency training director becomes involved in the last few months of training due to performance issues and after residents became alarmed by these cries for help. Unable to accept a new identity that incorporates the depressive illness, the resident continues to reject more aggressive treatment and refuses to embrace a recovering role- "I will not surrender my keys". The issue is dropped when the resident graduates and moves out of state. Outside the supervision of an academic setting where a vital recovering practitioner identity and skill repertoire could have been acquired, the graduated resident develops job failure and attempts suicide. 
Stage Six

Mental illness recovery stage

Intimacy versus isolation

Erikson developmental stage

Intimacy versus isolation

The sixth stage of recovery bears the same name as the corresponding Eriksonian stage, intimacy versus isolation. This recovery stage involves not so much feelings about socialization within society, but the challenge sometimes presented by disability in forming intimate relationships. Many people find that employment and peer relationships are more manageable than intimacy with a life partner. Individuals may lose partners due to the illness and/or struggle to establish new ones. If the individual maintains a close relationship after the onset of severe symptoms, the level of intimacy may change and be experienced as loss.

Beginning to date, especially if the individual experienced an early onset of disability and had little or no premorbid dating experience, may awaken intense feelings of anxiety and self-doubt. An individual with prior relationships devastated by the disability may become avoidant or despondent about the possibility of "trying again".

The dynamics involved in the "new self" versus "sick self" stage may be re-awakened as one wrestles with disclosing the disability to a new companion. Some people opt to search for a mate within the recovering community. This may place severe strain on both partners if frequent relapses destabilize each other's recovery. Anger and selfloathing may also re-emerge if a paramour flees the relationship after disclosure or during a witnessed relapse. Distinguishing anger generated by this recovery work from anger as a symptom of an impending relapse may be difficult. Here, long term continuity of care with one practitioner or stable relationships with knowledgeable peers is valuable in discerning whether the strong emotion is similar to previous relapses or related to the recovery work.

Many people during this stage befriend others less far along in the recovery process and develop mentoring relationships within the realm of peer-support contacts. This process has been found in models of addiction recovery to be crucial in resolving anger (Wilson Bill 2005) and appears to play a similar role for those with mental illness.

A 37 year old disabled, mental health advocate, diagnosed with paranoid schizophrenia attends his 20 year high school reunion and hooks up with a recently divorced former girlfriend unaware of his struggle with recovery. After spending a romantic weekend together, he impulsively confides details of his distant involvement in the criminal justice system due to his psychosis. The new-found lover immediately abandons the gentleman, changing her phone number and blocking his Email. Distraught, he goes to a NAMI Connection support group where he is a longstanding member. He receives support from several women who tell him the ex-girlfriend is the one with the problem and comment on his many wonderful qualities. He later begins casually dating one of the ladies in the group but confides to his therapist that her greater degree of disability may be too overwhelming for him to establish an intimate relationship with her.

One of the most important recovery issues addressed during the third through sixth stages is the consumer's struggle to completely master internalized anger and cultivate a feeling of peace concerning the presence of the disability. When this issue is successfully negotiated, the ability to express intimacy in peer relationships and acceptance of lifelong engagement within the process of recovery becomes integrated.

\section{Stage Seven}

\begin{tabular}{ll}
\hline Mental illness recovery stage & Purpose versus passivity \\
Erikson developmental stage & Generativity versus stagnation \\
\hline
\end{tabular}

The seventh recovery stage, purpose versus passivity, parallels Erikson's generativity versus stagnation stage and involves finding a life strategy for living well with a psychiatric disability despite sometimes disabling symptoms. Individuals use their repertoire of coping skills learned throughout the recovery process and spend their energy executing reasonable activities and goals. They may commit themselves to giving back to others or public service while they search and adopt a "life niche" which assists in resolution of this stage's conflict.

While recovery involves the pursuit of interests and productive activity at all stages, this "life niche" is defined by the consolidation of self-defined "purpose" into a distinct perceived life role that embraces the recovery experience. Resolution of this stage produces a sense of personal fulfillment with one's current life, the capacity to problem solve through conflicts and accept advice from others when needed. Individuals attempt to minimize the damage of recurrent episodes and utilize more complex defense mechanisms to handle conflicts. In the absence of treatment-related trauma, recovering people will often see providers as partners and embrace psychiatric treatment as a positive experience.

A 48 year old woman with severe panic disorder struggles with the uncertainty of getting off disability and pursuing a nursing degree. She begins developing escalating panic attacks when driving past the local nursing school or when confined to lecture rooms 
with large crowds. Her psychiatrist adjusts her medication while encouraging her to work with her therapist on a slower course for obtaining her degree. She begins volunteering for a mobile crisis unit that serves the homeless. After graduating as "the oldest nurse in my class", she accepts a full time job working with the same organization.

Seventh stage conflict involves the fear of severe relapse and the possibility of further periods of loss of control. Psychiatric advance directives may empower individuals with some level of comfort that wishes for treatment will be honored despite the temporary loss of capacity.

\section{Stage Eight}

Mental illness recovery stage

Integrity versus despair

Erikson developmental stage

Integrity versus despair

The eighth stage of recovery named exactly as the Eriksonian developmental stage, integrity versus despair, involves one's acceptance of the life changes brought about by the disability. Recovering individuals may mourn the lack of children or life partner and wonder how their life may have been different without the disability. Much as the elderly often process their aging by reviewing their lives, the person in recovery may address feelings concerning the symptoms by talking about past relapses. This helps to produce closure for grief, demonstrate the utilization of a repertoire of coping skills and affirms the recovered life that has arisen. While some people reach this stage at advancing age, many come to this point while still fairly youthful.

A 64 year old father of three became disabled with paranoid schizophrenia during his freshman year of college at a prestigious engineering school. While filming an advocacy video, he reflects on his life and the impact of his illness. "It's been horrible times mixed with periods of sublime joy-I think my mental illness has made me a kinder, gentler person and made me value my relationships with my family. My brother is a very successful lawyer who has divorced twice. His children refuse to spend Christmas with him and he'll have to work until death to pay off his debts. That could have been me."

\section{Discussion}

When discussing recovery, it is important to note that recovery is a mind-state-not a provider-determined level of occupational or psychosocial functioning. Recovery involves empowering one's self to live well. It is not tied to traditional provider-centered views of being "high functioning" nor "compliant". Over the last 15 years, more and more professional articles have documented large number of individuals who have experienced a disabling psychiatric condition and then came to embrace a fulfilling life that includes significant improvement in many life roles.(Ridgway 2001; Anthony 1993; Sullivan 1997). We are six of these individuals: our personal recovery experiences are the basis for this paper (Vogel-Scibilia 2001; Frese 1993; Baxter 1998; Rodrigez 2004). Some of us who provide direct clinical services practice these precepts within our professional practice.

First-person accounts of recovery that are designed as recovery narratives have become increasingly available over the last 20 years. These narratives help providers to understand the lived experience of mental illness and the current social context of a person's recovery (Kelley 1995). The use of narratives for persons in the process of recovery allows one to grieve the prior trauma related to the psychiatric disability while serving as an opportunity to revise the narrative over the time of the recovery work to emphasize a strength-based perspective of recovery. This can positively replace prior traditional care's deficitfocused, pathology-based perception that is often messaged to clients (Ridgway 2001). One timely article emphasizes findings from personal recovery narratives research that delineates eight personal recovery themes. All of these themes are contained within our model (see Table 4; Ridgway 2001). Using our model's eight recovery stages while providing personal narrative psychotherapy may give needed structure to these therapeutic interventions while promoting recovery in a mutually synergistic fashion.

The concept of psychiatric recovery includes the hopeful notion that, when progress towards living well may slow down or stop, it is a temporary situation. How far one has advanced on Erikson's schema for human development premorbidly plays a role in how much work is necessary to

Table 4 Concepts of recovery based on personal narrative research

Recovery is a reawakening of hope after despair

Recovery is breaking through denial and achieving understanding and acceptance

Recovery is moving from withdrawal to engagement and active participation in life

Recovery is active coping rather than passive adjustment

Recovery means no longer viewing oneself primarily as a person with a psychiatric disorder and reclaiming a positive sense of self

Recovery is moving from alienation to a sense of meaning and purpose

Recovery is a complex and non-linear journey

Recovery is not accomplished alone-the journey involves support and partnership

Formatted from text: Ridgway (2001) 
advance. This may explain why persons who have underlying developmental difficulties, or are younger at onset of illness, may have more difficulty with recovery. These individuals have to work through more new Eriksonian developmental conflicts while executing the corresponding recovery stages. Additionally, part of recovery may be hindered by unresolved developmental baggage carried along into later age.

When someone first becomes symptomatic, there is regression and a process of working through previously accomplished human development stages while commencing with recovery. Subsequent relapses cause microregressions within the recovery process. Working through previously addressed stages occurs more and more rapidly as competence is acquired in managing these episodes. The recovery process may be complicated by frequent relapses or persistent distressing symptoms. It may prove helpful to examine developmental conflicts through sequential relapses to see how much progress has occurred, and collaboratively gauge the ability of the individual to do the recovery work.

Regardless of where along the continuum of normal Eriksonian development the individual lies at onset of the disability, experience from previous dichotomy negotiations may be called upon to accelerate the recovery work. After one has renegotiated previously attained developmental stages and mastered the corresponding recovery stages, the process will continue through subsequent developmental and parallel recovery dichotomies. Sometimes, the borders between stages are really transition zones where adjoining issues are addressed simultaneously. Often, like the model of grief described by Dr. Kubler-Ross (1969), an individual may advance or regress between stages through out the course of recovery in a non-linear fashion. Most of the time and work is accomplished in the first three stages, while the next five stages may have more blurry boundaries and may be less conflict laden. The later five stages are negotiated more quickly if the individual's personality development has been supported and secure.

Another important concept involved in recovery theory involves resilience. Resilience is the ability to overcome symptoms or setbacks through recovery and/or developing positive adaption skills through learning. One of our authors sums this concept up in her personal account: Turn of the Tide (Baxter 1998). In her clinical work with clients, she uses the story of a turtle that just keeps on slowly moving forward until adversity hits. It curls up in its shell and takes care of itself. When things are better, it starts moving forward again. Her consultation room is filled with turtles (Solovitch 2007) which she keeps to emphasize the point. Often when friends or co-workers are having a clinical relapse, she gives them a turtle as a present. Use of tangible symbols of recovery or resilience may be very helpful in discussing recovery based concepts in clinical practice.

\section{Conclusion}

In summary, this model presents a helpful schema to integrate diverse recovery precepts into a useable clinical strategy for providers of psychiatric care. Recovering individuals do not recover in isolation but engage others in their recovery strategy (Ridgway 2001). While some psychiatric survivors may eschew help from organized psychiatry and state that persons with mental illness should design their recovery on their own (Rissmiller and Rissmiller 2006), many psychiatric providers appear interested in engaging and transforming prior traditional, paternalistic forms of care into recovery-based services. Utilizing precepts that spring from familiar theories in one's practice of fostering recovery is an excellent next step.

While the process of recovery and internalization of a healthy identity separate from the psychiatric disability may be a long-term process for some consumers, the nature of current consumer-focused psychiatric treatment-as well as peer support models-are well suited to address these goals.

Open Access This article is distributed under the terms of the Creative Commons Attribution Noncommercial License which permits any noncommercial use, distribution, and reproduction in any medium, provided the original author(s) and source are credited.

\section{References}

Anthony, W. A. (1993). Recovery from mental illness: The guiding vision of the mental health service system in the 1990s. Psychosocial Rehabilitation Journal, 16(4), 11-23.

Baxter, E. A. (1998). Personal accounts: Turn of the tide. Psychiatric Services (Washington, DC), 49, 1297-1298.

Bellack, A. S. (2006). Scientific and consumer models of recovery in schizophrenia: Concordance, contrasts and implications. Schizophrenia Bulletin, 32(3), 432-442. Epub 2006 Feb3.

Bilheimer, R. (1997). I'm Still Here- the Truth about Schizophrenia (video), Titusville, New Jersey, Janssen Pharmaceutica.

Burland, J. (2000). Family to Family Education Course. Arlington, Virginia: National Alliance on Mental Illness.

Collins, S., \& Cutliffe, J. R. (2003). Addressing hopelessness in people with suicidal ideation: Building upon the therapeutic relationship utilizing a cognitive behavioral approach. Journal of Psychiatric and Mental Health Nursing, 10(2), 175-185.

Davidson, L., Miller, R., \& Flanagan, E. (2008a). What's in it for me? The utility of psychiatric treatments from the perspective of the person in recovery. Epidemiologia e Psichiatria Sociale, 17(3), $177-181$.

Davidson, L., Schmutte, T., Dinzeo, T., \& Andres-Hyman, R. (2008b). Remission and recovery in schizophrenia: Practitioner and patient perspectives. Schizophrenia Bulletin, 34(1), 5-8. doi:10.1093/schbul/sbm122. Epub 2007 Nov 5. 
Davidson, L., \& Strauss, J. S. (1992). Sense of self in recovery from severe mental illness. The British Journal of Medical Psychology, 65(Pt2), 131-145.

Davidson, L., \& Strauss, J. S. (1995). Beyond the biopsychosocial model: Integrating disorder, health and recovery. Psychiatry, 58, 44-55.

DeMelle, L. (2002). In our own voice-recovery education presentation. Arlington, Virginia: National Alliance on Mental Illness.

Drake, R. E. (2000). Introduction to a special series on recovery. Community Mental Health Journal, 36(2), 207-208. doi:10.1023/ A:1001850528874.

Erikson, E. (1968). Identity: Youth in Crisis (p. 94). New York: W.W. Norton.

Farkas, M. (2007). The vision of recovery today: What it is and what it means for services. World Psychiatry; Official Journal of the World Psychiatric Association (WPA), 6(2), 68-74.

Frese, F. J. (1993). Cruising the cosmos, part three: psychosis and hospitalization. A consumer's personal recollection. In A. B. Hatfield \& H. P. Lefly (Eds.), Surviving mental illness. New York: Guilford Press.

Frese, F. J., Stanley, J., Kress, K., \& Vogel-Scibilia, S. E. (2001). Integrating recovery-based practices and the recovery model. Psychiatric Services (Washington, DC), 52(11), 1462-1468. doi:10.1176/appi.ps.52.11.1462.

Jacobson, N., \& Greenley, D. (2001). What is recovery? A conceptual model and explication. Psychiatric Services (Washington, DC), 52(4), 482-485. doi:10.1176/appi.ps.52.4.482.

Kubler-Ross, E. (1969). On death and dying. New York, NY: Simon and Schuster.

Linehan, M. (1993). Skills training manual for treating borderline personality disorder (pp. 163-164). New York, NY: The Guilford Press.

McNulty, K. (2006). Peer to peer recovery course. Arlington, VA: National Alliance on Mental Illness.

Mead, S., \& Copeland, M. E. (2000). What recovery means to us: Consumer perspectives. Community Mental Health Journal, 36(3), 315-328. doi:10.1023/A:1001917516869.

Resnick, S. G., Fontana, A., Lehman, A. F., \& Rosenheck, R. A. (2005). An empirical conceptualization of the recovery orientation. Schizophrenia Research, 75(June), 119-128. doi:10.1016/ j.schres.2004.05.009.

Resnick, S. G., Rosenheck, R. A., \& Lehman, A. F. (2004). An exploratory analysis of recovery. Psychiatric Services (Washington, DC), 55(5), 540-547. doi:10.1176/appi.ps.55.5.540.

Ridgway, P. (2001). ReStorying psychiatric disability: Learning from first person recovery narratives. Psychiatric Rehabilitation Journal, 24(4), 335-343.
Rissmiller, D., \& Rissmiller, J. (2006). Evolution of the antipsychiatry movement into mental health consumerism. Psychiatric Services (Washington, DC), 57(6), 863-866. doi:10.1176/appi.ps.57.6.863.

Rodrigez, M. (2004). My story: Steve Miller-Living the good life. Summer, 2(3) 50.

Rogers, J. A., Vergare, M. J., Baron, R. G., \& Salzer, M. S. (2007). Barriers to recovery and recommendations for change: The pennsylvania consensus conference on psychiatry's role. Psychiatric Services (Washington, DC), 58(8), 1119-1123. doi:10. 1176/appi.ps.58.8.1119.

Schrank, B., Stanghellini, G., \& Shade, M. (2008). Hope in psychiatry: a review of the literature. Acta Psychiatrica Scandinavica, 10 October 2008. Epub ahead of print.

Shattell, M. M., Starr, S. S., \& Thomas, S. P. (2007). 'Take my hand, help me out': Mental health service recipients' experience of the therapeutic relationship. International Journal of Mental Health Nursing, 16(4), 274-284. doi:10.1111/j.1447-0349.2007.00477.x.

Solovitch, S. (2007). Conspiracy of silence. BP magazine, 3(1), 28-34.

Sullivan, W. P. (1997). Strengths, niches and recovery from serious mental illness. In D. Saleebey (Ed.), The strengths perspective in social work practice (2nd ed.). New York: Longman.

United States Department of Health and Human Services. (2005). National Consensus Statement on Mental Health Recovery. Retrieved, 10/27(08). http://mentalhealth.samhsa.gov/publications/ allpubs/sma05-4129/ p. 1-3.

Vogel-Scibilia, S. E. (2001). Reflections on recovery. NAMI Advocate, Winter 5-6.

Vogel-Scibilia, S. E. (2002-2008). Multiple presentations to the medical and consumer community including National SelfDetermination Consumer Conference, Chicago, Illinois, February 2002; National Alliance for The Mentally Ill Annual Conference, Minneapolis Minnesota, June 2003; Grand Rounds Allegheny General Hospital, Pittsburgh, Pennsylvania, May 2004; NAMI Louisiana Annual Conference, September 2004: NAMI Pennsylvania 2004 Annual Conference, October 2004; Butler County Recovery Conference, Butler, Pennsylvania, May 2005; Russian Congress of Psychiatry, Moscow, Russia, November 2005; Western Virginia Recovery Conference, Western State Hospital, Staunton, Virginia, December 2005, World Psych Rehabilitation Conference, Athens, Greece, 2007, World Psychiatric Association Conference, Istanbul, Turkey, 2006, NAMI National Grand Rounds, February, 2008.

Wilson Bill. (2005). Alcoholics Anonymous (4th ed., pp. 72-88). New York: Alcoholics Anonymous World Services Inc. 